\title{
ROUGH STATISTICAL CONVERGENCE OF SEQUENCES OF FUZZY NUMBERS
}

\author{
SHYAMAL DEBNATH and DEBJANI RAKSHIT
}

\begin{abstract}
In this paper we introduce the notion of rough statistical convergence in the fuzzy setting, which generalizes rough convergence of sequences of fuzzy numbers. We define the set of rough statistical limit points of a sequence of fuzzy numbers and prove some results associated with these notions.
\end{abstract}

MSC 2010. 40A05, 03E72.

Key words. Fuzzy number sequence, rough convergence, statistical convergence, statistical cluster points.

\section{REFERENCES}

[1] F. Akcay and S. Aytar, Rough convergence of a sequence of fuzzy numbers, Bull. Math. Anal. Appl., 7 (2015), 17-23.

[2] S. Aytar, Statistical limit points of sequences of fuzzy numbers, Information Sciences, 165 (2004), 129-138.

[3] S. Aytar, The rough limit set and the core of a real sequence, Numer. Funct. Anal. Optim., 29 (2008), 283-290.

[4] S. Aytar, Rough statistical convergence, Numer. Funct. Anal. Optim., 29 (2008), $291-$ 303.

[5] S. Aytar, Rough statistical cluster points, Filomat, 31 (2017), 5295-5304.

[6] S. Debnath and J.Debnath, Some generalized statistical convergent sequence spaces of fuzzy numbers via ideals, Math. Sci. Lett., 2 (2013), 151-154.

[7] S. Debnath and J.Debnath, Some ideal convergent sequence spaces of fuzzy real numbers, Palest. J. Math., 3 (2014), 27-32.

[8] S. Debnath and D. Rakshit, On rough convergence of fuzzy numbers based on $\alpha$-level sets, J. Indian Math. Soc. (N.S.), 85 (2018), 42-52.

[9] S. Debnath and D. Rakshit, On I-statistical convergence, Iranian J. Math. Sci. Inform., 13 (2018), 101-109.

[10] H. Fast, Sur la convergence statistique, Colloq. Math., 2 (1951), 241-244.

[11] J.A. Fridy, On statistical convergence, Analysis (Berlin), 5 (1985), 301-313.

[12] J.A. Fridy, Statistical limit points, Proc. Amer. Math. Soc., 4 (1993), 1187-1192.

[13] J.A. Fridy and C. Orhan, Statistical limit superior and limit inferior, Proc. Amer. Math. Soc., 125 (1997), 3625-3631.

[14] M. Matloka, Sequence of fuzzy numbers, Busefal, 28 (1986), 28-37.

[15] S. Nanda, On sequences of fuzzy numbers, Fuzzy Sets and Systems, 33 (1989), 123-126.

The authors would like to thank the referee(s) for their valuable and useful comments, which helped the improvement of this work to the present form.

DOI: $10.24193 /$ mathcluj.2019.1.03 
[16] F. Nuray and E. Savas, Statistical convergence of sequences of fuzzy numbers, Math. Slovaca, 45 (1995), 269-273.

[17] H.X. Phu, Rough convergence in normed linear spaces, Numer. Funct. Anal. Optim., 22 (2001), 199-222.

[18] H.X. Phu, Rough convergence in infinite dimensionnal normed spaces, Numer. Funct. Anal. Optim., 24 (2003), 285-301.

[19] M.L. Puri and D.A. Ralescu, Differential of fuzzy numbers, J. Math. Anal. Appl., 91 (1983), 552-558.

[20] E. Savas, A note on sequence of fuzzy numbers, Inform. Sci., 124 (2000), 297-300.

[21] B.C. Tripathy, On statistically convergent and statistically bounded sequences, Bull. Malays. Math. Sci. Soc., 20 (1997), 31-33.

[22] B.C. Tripathy and S. Debnath, On generalized difference sequence spaces of fuzzy numbers, Acta Scientiarum: Technology, 35 (2013), 117-121.

[23] B.C. Tripathy and R. Goswami, Fuzzy real valued p-absolutely summable multiple sequences in probabilistic normed spaces, Afr. Mat., 27 (2015), 1281-1289.

[24] B.C. Tripathy and M. Sen, On lacunary strongly almost convergent double sequences of fuzzy numbers, An. Univ. Craiova Ser. Mat. Inform., 42 (2015), 254-259.

[25] L.A. Zadeh, Fuzzy sets, Information and Control, 8 (1965), 338-353.

Received February 9, 2018

Accepted June 19, 2018

Tripura University (A Central University)

Department of Mathematics

Suryamaninagar-799022, Agartala, India

E-mail: shyamalnitamath@gmail.com

ICFAI University Tripura

Department of FST

Kamalghat-799210, West Tripura, India

E-mail: debjanirakshit88@gmail.com 